\title{
Effect of Fungal Extracts on Bacillus thuringiensis Serotypes Causing Flacherie Disease in Mulberry Silkworm, Bombyx mori L.
}

\author{
R. Saravana Kumar ${ }^{1 *}$, P. Sudhakara Rao ${ }^{1^{*}}$, K. M. Vijaya Kumari ${ }^{1}$ and R. K. Mishra ${ }^{2}$ \\ ${ }^{1}$ Silkworm Seed Technology Laboratory, Central Silk Board, Kodathi, \\ Bangalore-500 035, India \\ ${ }^{2}$ National Silkworm Seed Organization, Central Silk Board, Banglore-560068, India \\ *Corresponding author
}

\section{A B S T R A C T}

Keywords

Silkworm,

Flacherie, Bacillus

thuringiensis,

Fungal extract,

Metabolite,

Antibacterial

activity

Article Info

Accepted:

08 January 2020

Available Online:

10 February 2020
Antibacterial activity of six different species of fungal extracts viz., Aspergillus ochraceous, Paecilomyces variotii, Schizophyllum sp., Epicoccum sp., Metarhizium sp., Aspergillus niger were evaluated against ten serotypes of Bacillus thuringiensis to develop new bioactive secondary metabolites from the microbial sources. Fungal crude extracts were isolated by ethyl acetate solvent extraction method and product yields varied from $0.150 \mathrm{~g}$ to $0.538 \mathrm{~g}$. Thin Layer Chromatography was carried out for detecting the small molecule compounds present in the crude extracts. Antibacterial activities of fungal extracts were analyzed by disc diffusion method. All ten B.t serotypes were inhibited by six fungal extracts with zone of inhibition ranging from $12 \pm 1.73$ to $36 \pm 1.53$. Among the six extracts Paecilomyces variotii showed highest inhibition of $36 \mathrm{~mm}$ against B.t sotto. In vitro and in vivo studies conducted for the effect of extracts with different concentration and exposure duration reveals that effective against all serotypes. The results suggested that the Microbial derived extracts could be a new source of alternative in developing an effective bioactive molecule for the management of silkworm bacterial diseases.

\section{Introduction}

Diseases are the most important limiting factor affecting silkworm, Bombyx mori L., known for the production of silk cocoons are generally affected by viral, fungal and protozoan pathogens among which bacterial pathogens alone cause cocoon loss about 7.5 to 20.0 percent (Selvakumar, 2013). The major fact responsible for bacterial flacherie was the rearing conditions, rise in temperature and humidity in rearing place, insufficient bed spacing leads to dysfunction of alimentary canal which encourages flacherie (Nataraju $e t$ al., 2005). Bacillus thuringiensis (Bt) is one of the causative agents for flacherie disease and the impact was high in silkworm larvae (Nishiit sutsuj et al., 1979). Bt is a Gram positive spore forming bacterium characterized by the formation of parasporal inclusions during sporulation (Ohba, 1996). After being ingested by the larvae, the parasporal inclusions are dissolved in larval midgut juice and release protoxins. The 
activated toxins interact with the larval epithelial membrane and induce pore formation in the membrane, which ultimately leads to insect death (Gill et al., 1992). Larvae affected by $B t$ lose their appetite, undergo convulsions and their bodies become stretched and cracked. The cadavers gradually become brown to black-brown and finally when rotting they turn black with fowling smell (Aruga, 1994). Researchers have come out with different sources of bioactive compounds/crude extracts from plants to prevent the silkworm bacterial pathogens (Selvakumar et al., 2001; Manimegalai and Chandramohan, 2005; Priyadharshini, 2008) but limited attempts were made for the use of microbial metabolites. In the present study, the efficacy of fungal extracts controlling the ten serotypes of $B t$ causing flacherie disease in mulberry silkworm was evaluated to develop a effective bioactive molecules for the control of disease.

\section{Materials and Methods}

\section{Microbial materials}

Six different fungal cultures viz., Aspergillus ochraceous, Paecilomyces variotii (Fig.1), Schizophyllum sp., Epicoccum sp., Metarhizium sp., Aspergillus niger were procured from culture collection centre, NCL, Pune, India for extraction of fungal product. These cultures were maintained at $4{ }^{\circ} \mathrm{C}$ and sub cultured in Potato dextrose agar slants. Ten Bacillus thuringiensis serotypes viz., tolworthi, aizawai, japonensis, sotto, kenyae, israelensis, morrisoni, kurstaki, thuringiensis, alest $i$ were collected and maintained for the experiments.

\section{Preparation of fungal extract}

Fungal strains were grown in PDA culture medium at $28{ }^{\circ} \mathrm{C}$ for 5 days after that cultures were cut into solid discs $\left(1 \mathrm{~cm}^{2}\right)$ and inoculated into $1000 \mathrm{ml}$ Potato dextrose broth in Erlenmeyer flasks. These cultures were grown with continuous shaking of $200 \mathrm{rpm}$ at $25 \pm 2{ }^{\circ} \mathrm{C}$ in shaking incubator for fifteen days. At the end of incubation, the fungal mycelium and the culture medium were separated by filtration using Whatmann filter No.3. The filtered supernatant was extracted thrice with equal volume of ethyl acetate. The combined organic phase was dried with anhydrous sodium sulphate and concentrated in reduced vacuum evaporator at $45^{\circ} \mathrm{C}$. The crude extract dissolved in $10 \%$ dimethylsulfoxide (DMSO) and kept in $4{ }^{\circ} \mathrm{C}$ for further use.

\section{Identification of small molecules}

Thin Layer Chromatography technique was used for detecting the small molecule compounds present in the fungal crude extracts. The extract samples were spotted on silica plates and eluted in a TLC chamber with ethyl acetate and hexane as the mobile phase in the ratio 8:2. The plates were then air dried and visualized by exposing to iodine vapor.

\section{In vitro antibacterial activity by disc} diffusion

Antimicrobial susceptibility test was carried out by the disc diffusion method. Overnight incubated $B t$ cultures $\left(1 \times 10^{8}\right.$ spores $\left./ \mathrm{ml}\right)$ spread on a Muller Hinton Agar plate. Whatman No.1 filter paper discs (6 $\mathrm{mm}$ diameter) dipped in the extract concentration of $50 \mathrm{mg} / \mathrm{ml}$ solution and kept on inoculated plates. Ampicillin $(10 \mathrm{mcg})$ was used as positive control. The plates inoculated with bacteria were made in triplicate and incubated at $32 \pm 1^{\circ} \mathrm{C}$ for 48 hours. The development of zone around the disc diameter was measured in millimeters. All data were analyzed through Microsoft Excel for Windows. 


\section{Efficacy of minimum antibacterial concentration}

The effect of different concentrations of fungal product for minimum germicidal activity was tested in vitro against $B$. thuringiensis serotypes $\left(1 \times 10^{8} \mathrm{cells} / \mathrm{ml}\right)$. These pathogens were suspended separately in different concentrations of fungal product (0.25 to $4 \%$ ) for different durations $30 \mathrm{~min}, 1$ hour and 2 hour at room temperature. After this incubation, samples were inoculated in Louria Bertani agar plate and incubated at $32 \pm 1^{\circ} \mathrm{C}$ for 48 hours. The experiment conducted in triplicate. The minimum bactericidal activity was determined by the lowest concentration of fungal product incubated with pathogens were completely killed.

\section{In vivo activity of fungal extract}

The antibacterial activity of the product with different concentrations tested in vivo against Bacillus thuringiensis serotypes $\left(1 \times 10^{8}\right.$ cells $/ \mathrm{ml})$. These pathogens suspended to the various concentrations of product and incubated at $25 \pm 2^{\circ} \mathrm{C}$ for different duration (30 min, 1 hour and 2 hour). After the treatment, samples centrifuged, washed and used for inoculation to determine the infectivity of the pathogens. $0.5 \mathrm{ml}$ of this sample orally inoculated to third instar larvae.

In positive control, viable pathogens inoculated without treatment to the larvae and in negative control, without inoculation larvae reared for comparative study in three replications. All the batches were reared till spinning and allowed to spin the cocoons. Observations recorded for disease development and mortality. Treatment effects were analyzed to determine the differences between the treatment means of extract concentration.

\section{Results and Discussion}

\section{Screening of small molecules}

Antibacterial activities of the fungal extracts isolated from six different fungi were analyzed to derive high active biomolecules for treatment of $B t$ serotypes. The crude extract of fungal product yields varied from $0.150 \mathrm{~g}$ to $0.538 \mathrm{~g}$. A range of yields among extracts was observed depending on the fungal material used.

The maximum extraction yield was obtained from Schizophyllum sp. with $0.538 \mathrm{~g}$ and $P$. variotii exhibited the lowest extraction yield of $0.150 \mathrm{~g}$. Thin Layer Chromatography was carried out for detecting the small molecule compounds present in the crude extracts and 2 to 5 product spots were appeared in all fungal extract in the range of 0.2 to 0.84 retention factor $(R f)$ with ethyl acetate as mobile phase for the extract.

\section{In vitro antibacterial activity}

In vitro studies results showed that all six fungal extracts exhibited antibacterial activity in the range of $12 \pm 1.73$ to $36 \pm 1.53$ against Bt serotypes (Table 1), (Fig.2 \& 3). The maximum activity of $36 \pm 1.53 \mathrm{~mm}$ observed in $P$. variotii and $29 \pm 1.00$ in A. ochraceus against sotto and followed by $28 \pm 0.58 \mathrm{~mm}$ in diameter against japonensis by Epicoccum sp. In particular, P. variotii and Epicoccum $s p$. showed above $20 \mathrm{~mm}$ inhibition against all serotypes of $B t$ except kenyae and tolworthi respectively. Among the six extracts, Metarhizium sp. exhibited lowest activities observed in all $B t$ bacteria except against sotto which was $25 \pm 1.00 \mathrm{~mm}$ in diameter of growth inhibition. Ampicillin (10 $\mathrm{mg}$ ) was used as positive control and results indicated that the extracts showed almost equivalent activity at low concentrations. 
Table.1 Antibacterial activity of the fungal extract against $B T$ serotypes. Zone of inhibition measured in diameter $(\mathrm{mm})$ mean $\pm \mathrm{SD}$

\begin{tabular}{|l|r|r|r|r|r|r|}
\hline $\begin{array}{l}\text { BT } \\
\text { serotypes }\end{array}$ & $\begin{array}{l}\text { Aspergillus } \\
\text { ochraceus }\end{array}$ & $\begin{array}{l}\text { Paecilomyces } \\
\text { variotii }\end{array}$ & $\begin{array}{l}\text { Schizophyllum } \\
\text { sp. }\end{array}$ & $\begin{array}{l}\text { Epicoccum } \\
\text { sp. }\end{array}$ & $\begin{array}{l}\text { Metarhizium } \\
\text { sp. }\end{array}$ & $\begin{array}{l}\text { Aspergillus } \\
\text { niger }\end{array}$ \\
\hline tolworthi & $12 \pm 1.73$ & $22 \pm 2.08$ & $16 \pm 3.21$ & $17 \pm 1.00$ & $13 \pm 1.73$ & $13 \pm 1.15$ \\
\hline aizawai & $22 \pm 1.53$ & $20 \pm 1.00$ & $18 \pm 1.15$ & $20 \pm 0.00$ & $16 \pm 0.58$ & $16 \pm 2.00$ \\
\hline japonensis & $21 \pm 1.15$ & $20 \pm 1.00$ & $23 \pm 0.58$ & $28 \pm 0.58$ & $15 \pm 0.58$ & $24 \pm 0.58$ \\
\hline sotto & $29 \pm 1.00$ & $36 \pm 1.53$ & $22 \pm 1.15$ & $24 \pm 2.00$ & $25 \pm 1.00$ & $24 \pm 0.58$ \\
\hline kenyae & $26 \pm 1.15$ & $17 \pm 1.15$ & $25 \pm 1.73$ & $26 \pm 1.15$ & $18 \pm 1.15$ & $23 \pm 1.73$ \\
\hline israelensis & $14 \pm 3.61$ & $23 \pm 1.00$ & $19 \pm 1.15$ & $20 \pm 0.58$ & $20 \pm 1.73$ & $19 \pm 2.31$ \\
\hline morrisoni & $21 \pm 1.15$ & $22 \pm 1.53$ & $21 \pm 1.53$ & $21 \pm 2.31$ & $17 \pm 1.73$ & $18 \pm 2.52$ \\
\hline kurstaki & $13 \pm 2.52$ & $22 \pm 1.15$ & $21 \pm 1.73$ & $20 \pm 1.73$ & $23 \pm 1.15$ & $21 \pm 1.15$ \\
\hline thurigiensis & $17 \pm 1.53$ & $22 \pm 3.00$ & $23 \pm 2.08$ & $21 \pm 2.00$ & $21 \pm 2.65$ & $19 \pm 2.00$ \\
\hline alesti & $20 \pm 1.53$ & $25 \pm 1.15$ & $21 \pm 2.31$ & $24 \pm 1.53$ & $18 \pm 2.65$ & $23 \pm 3.51$ \\
\hline
\end{tabular}

Table.2 In vitro testing of $P$. variotii extracts with different concentrations and treatment

\begin{tabular}{|c|c|c|c|c|c|c|c|c|c|c|c|c|c|c|c|c|c|c|}
\hline \multirow[t]{2}{*}{ BT serotypes } & \multicolumn{6}{|c|}{$30 \mathrm{~min}$ Treatment } & \multicolumn{6}{|c|}{1 hour Treatment } & \multicolumn{6}{|c|}{2 hour Treatment } \\
\hline & 0.25 & 0.5 & 1 & 2 & 4 & $\mathrm{C}+$ & 0.25 & 0.5 & 1 & 2 & 4 & $\mathrm{C}+$ & 0.25 & 0.5 & 1 & 2 & 4 & $\mathrm{C}+$ \\
\hline tolworthi & + & + & + & - & - & + & + & + & + & - & - & + & + & + & - & - & - & + \\
\hline aizawai & + & + & + & - & - & + & + & + & + & - & - & + & + & + & - & - & - & + \\
\hline japonensis & + & + & + & - & - & + & + & + & + & - & - & + & + & + & - & - & - & + \\
\hline sotto & + & + & + & - & - & + & + & + & + & - & - & + & + & + & - & - & - & + \\
\hline kenyae & + & + & + & - & - & + & + & + & + & - & - & + & + & + & - & - & - & + \\
\hline israelensis & + & + & + & - & - & + & + & + & + & - & - & + & + & + & - & - & - & + \\
\hline kurstaki & + & + & + & - & - & + & + & + & + & - & - & + & + & + & - & - & - & + \\
\hline morrisoni & + & + & + & - & - & + & + & + & + & - & - & + & + & + & - & - & - & + \\
\hline thurigiensis & + & + & + & - & - & + & + & + & + & - & - & + & + & + & - & - & - & + \\
\hline alesti & + & + & + & - & - & + & + & + & + & - & - & + & + & + & - & - & - & + \\
\hline
\end{tabular}

(-) effective (+) not effective

Table.3 In vivo activity of fungal extract $P$. variotii with different exposure time

\begin{tabular}{|c|c|c|c|c|c|c|c|c|c|c|c|c|c|c|c|}
\hline \multirow[t]{2}{*}{ BT serotypes } & \multicolumn{5}{|c|}{30 min Treatment } & \multicolumn{5}{|c|}{1 hour Treatment } & \multicolumn{5}{|c|}{2 hour Treatment } \\
\hline & 1 & 2 & 4 & $\mathrm{C}+$ & $\mathrm{C}-$ & 1 & 2 & 4 & $\mathrm{C}+$ & C - & 1 & 2 & 4 & $\mathrm{C}+$ & $\mathrm{C}-$ \\
\hline tolworthi & + & - & - & + & - & + & - & - & + & - & - & - & - & + & - \\
\hline aizawai & + & - & - & + & - & + & - & - & + & - & - & - & - & + & - \\
\hline japonensis & + & - & - & + & - & + & - & - & + & - & - & - & - & + & - \\
\hline sotto & + & - & - & + & - & + & - & - & + & - & - & - & - & + & - \\
\hline kenyae & + & - & - & + & - & + & - & - & + & - & - & - & - & + & - \\
\hline israelensis & + & - & - & + & - & + & - & - & + & - & - & - & - & + & - \\
\hline kurstaki & + & - & - & + & - & + & - & - & + & - & - & - & - & + & - \\
\hline morrisoni & + & - & - & + & - & + & - & - & + & - & - & - & - & + & - \\
\hline thurigiensis & + & - & - & + & - & + & - & - & + & - & - & - & - & + & - \\
\hline alesti & + & - & - & + & - & + & - & - & + & - & - & - & - & + & - \\
\hline
\end{tabular}

(-) effective (+) not effective C+ positive control (Inoculated) C- Negative control (No inoculation) 
Fig.1 Culture growth of $P$. variotii on PDA medium

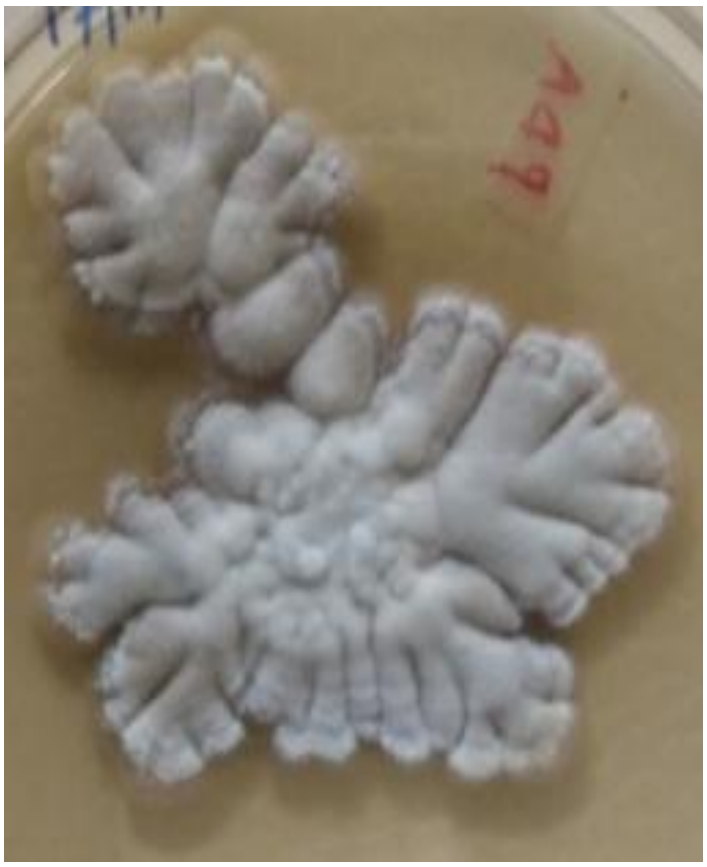

Fig.2 Zone of inhibition formed against the $B t$ serotypes by fungal extracts
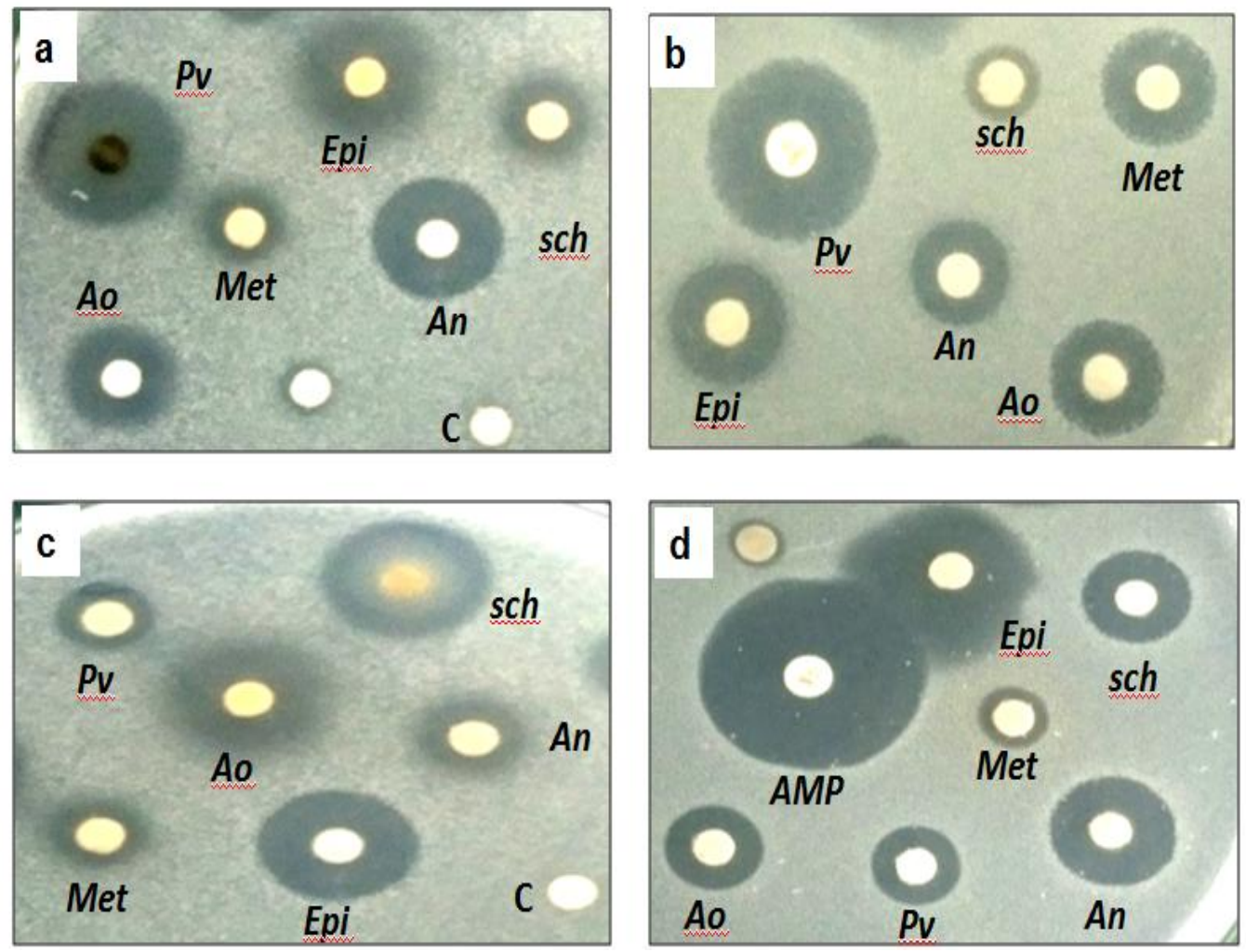

a- alesti, b - sotto, c- kenyae, d - japonensis. A.o - Aspergillus ochraceus, P.v- Paecilomyces variotii, schiSchizophyllum sp., Epi- Epicoccum sp., Met-Metarhizium sp., A.n-Aspergillus niger, C- control, AMP- Ampicillin 
Fig.3 Antibacterial activity of the Secondary metabolites extracted from the fungi against $B T$ serotypes

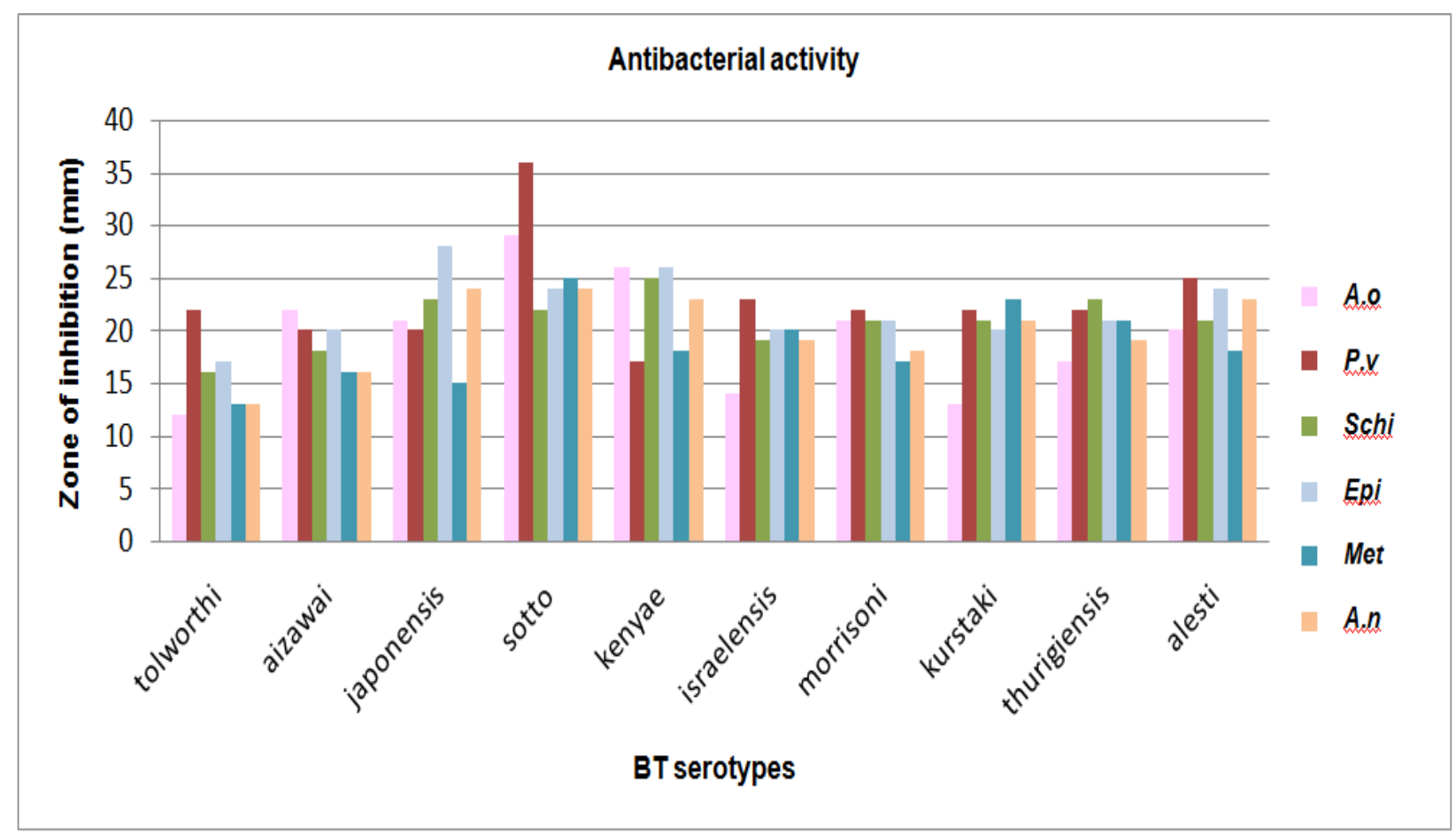

A.o - Aspergillus ochraceus, P.v- Paecilomyces variotii, schi- Schizophyllum sp., Epi- Epicoccum sp., MetMetarhizium sp., A.n-Aspergillus niger

\section{Efficacy of minimum antibacterial concentration}

$P$. variotii performed well in all serotypes and considered for minimum efficiency of concentration in vitro and in vivo studies. The extract was prepared in various percentage of concentration with different exposure duration (Table 2). In that $30 \mathrm{~min}$ exposure duration with the extract, 2 and $4 \%$ concentrations are effective and observed devoid of colonies. Up to $1 \%$ concentration was not effective and 10 to 50 bacterial colonies observed in $0.5,1 \%$ and more than 300 colonies was observed in $0.025 \%$ extract on the LB medium incubated for 48 hours. In 1 hour treatment similar trend was observed but number of colonies was less than the 30 min duration. In 2 hour duration, $1 \%$ extract onwards effective in all serotypes.

\section{In vivo activity of extracts}

An in vivo study reveals that $1 \%$ concentration of $P$. variotii extract effective for only 2 hour incubation, $2 \%$ and $4 \%$ extract was effective for all three exposed durations against $B t$ serotypes (Table 3). In positive control, without treatment larvae were infected by the pathogens but mortality rate was varied for all $B t$ serotypes. Bt morrsoni infected larvae died within 24 hours after inoculation of pathogen followed by japonensis, tolworthi, aizawai, sotto, alesti and less mortality rate was observed in kenyae, israelensis, kurstaki, thuringiensis with the influence of toxicity, temperature and/or food quality. Similar results reported by Selvakumar, (2013) stated that environmental factors have little impact on the mortality through toxicity and not infection by the bacteria. 
Bacillus thuringiensis is a widely distributed facultative entomogenous bacterium well known for bio pesticide and employed extensively against insect pests in agriculture but they are pathogenic to the silkworm (Selvakumar et al., 1999). Mahmoud et al., (2019) reported that black seed and basil leaves extracts treated with Bacillus thuriengiensis infected larvae significantly decreased larval mortality in B. mori.

Similarly, aqueous extract of Thuja orientalis (Manimegalai and Chandramohan, 2005), leaf extract of Aegle marmelos and bark extracts of $T$. orientalis (Manimegalai et al., 2010) were effective in managing $B t$ infected $B$. mori. Similar observation was indicated by Mohanta et al., (2013) extracts of $C$. zeylenicum, C. longa, Z. officinale showed a strong antibacterial activity against Flacherie pathogens. The secondary metabolites have no apparent metabolic, physiologic and structural role in the producer, but have effects on other organisms function as biochemical defence (Jain et al., 2004). Zhang et al., (2011) isolated four active secondary metabolite (Cerebroside C, Cerebroside D, 2Hydroxybenzyl alcohol, and 2-(4Hydrroxypheny) ethanol) from the Paecilomyces sp. In the present study $\mathrm{P}$. Variotii showed highest activity against all $B t$ pathogens and this might be presence of these compounds in the extract. Similar results reported by Oliveira et al., (2009) P. variotii extracts inhibited eight clinical isolates of entericococcs bacterial in the ranging from 25 to $35.25 \mathrm{~mm}$.

These results indicated that the possibility of the presence of highly active bioactive compounds/ secondary metabolites in the fungal crude extract. It is concluded that further studies are required to find out the bioactive compounds/ secondary metabolite responsible for the activity. Microbial derived products may be a source of alternative active compounds for control of silkworm diseases and it is a new approach in silkworm management.

\section{Acknowledgement}

The authors are thankful to Central Silk Board (Project ARP 3634) for supporting the work and thankful to the Technical staff of Seed pathology section for assistance in experiments, rearing and data collection.

\section{References}

Aruga, H. (1994). Principles of Sericulture (translated from Japanese). A. A. Balkema, Rotterdam.

Gill, S.S. E.A. Cowles \& P.V. Pietrantonio (1992). The mode of action of Bacillus thuringiensis endotoxins. Ann. Rev. Entomol. 37: 615-636.

Jain R, Nagpal S, Jain S, Jain S.C (2004) Chemical and biochemical evaluation of Bauhinia species. $J$ of Medicinal and Aromatic Plant Sciences; 26(1): 48-50.

Mahmoud S. I. Saad, Enas M. Y. Elyamani and Walaa M. M. Helaly (2019) Controlling of bacterial and fungal diseases that contaminating mulberry silkworm, Bombyx mori by using some plant extracts. Bulletin of the National Research Centre 43:172. 1-9. Manimegalai S, Adhithya R, Vellaikumar S, Paramasivam M, Chandrasekaran S (2010) Separation and characterization of antibacterial compounds from Aegle marmelos Correa and Thuja orientalis L. against silkworm pathogens. Int J Genet Eng Biotech. 1(3):177-186.

Manimegalai, S and N. Chandramohan (2005) Botanicals for the management of bacterial flacherie of silkworm, Bombyx mori L. Sericologia, 45(1): 55-58. 
Mohanta MK, Saha AK, Saleh DKMA, Hasan MA (2013) Bioefficacy of some plant extracts against pathogenic bacteria isolated from diseased silkworm larvae. Rajshahi Univ Zool Soc 32:0914.

Nataraju B., Sathyaprasad K, Manjunath D. Aswani Kumar C (2005) Silkworm crop protection. Central silk board, 6185.

Nishiit sutsuji, Uwo J, Endo Y (1979) Mode of action of Bacillus thurigiensis data endotoxin. Indian J Seric; 40(1):103103.

Ohba M., (1996) Bacillus thuringiensis populations naturally occurring on mulberry leaves: a possible source of the populations associated with silkworm rearing insectaries. $J$. Applied Bacteriology. 80, (1) 56-64.

Oliveira silva MR., Xisto Sena K and Buarque Gusmao N (2009) Secondary metabolites produced by endophytic fungus Paecilomyces variotii Bainier with antimicrobial activity against Enterococcus faecalis. Current Res. Topics in Microbial and Microbial Biotech. pp 519-522.
Priyadharshini, P., C. A. Mahalingam and K. R. Shashidhar (2008) Identification and characterization of bacterial pathogens in silkworm, Bombyx mori L. Current Biotica, 2(2): 181-191.

Selvakumar T, M. Balavenkatasubbiah and B. Nataraju (2001) Studies on Prevention or suppression of flacherie in silkworm, Bombyx mori L. Annual Report, Central Sericultural Research and Training Institute, Mysore. pp.45.

Selvakumar T (2013) Prevalence of flacherie disease and pathogenicity of isolated pathogens in silkworm, Bombyx mori (L.) Under different environmental conditions. Agri.Sci Digest (33):253258.

Selvakumar T., Nataraju, B. and Datta, R.K. (1999) Characterization of Bacillus thuringiensis varieties in relation to pathogenicity to silkworm, Bombyx mori, Indian Journal of Sericulture, 38(1):75-78

Zhan YG, Yuan WP, Xia XK, Jia AR, Liu X, Zhang MS, Liu CH (2011) The study of the secondary metabolites from fungus Paecilomyces sp. Zhong Yao Cai 34 (5): 707-709.

\section{How to cite this article:}

Saravana Kumar, R., P. Sudhakara Rao, K. M. Vijaya Kumari and Mishr, R. K. 2020. Effect of Fungal Extracts on Bacillus thuringiensis Serotypes Causing Flacherie Disease in Mulberry Silkworm, Bombyx mori L.. Int.J.Curr.Microbiol.App.Sci. 9(02): 1575-1582. doi: https://doi.org/10.20546/ijcmas.2020.902.181 